\title{
Trauma care in Malawi: A call to action
}

\section{Wakisa Mulwafu' ${ }^{1}$ Linda Chokotho ${ }^{2}$, Nyengo Mkandawire ${ }^{1}$, Hemant Pandit ${ }^{3}$, Dan L. Deckelbaum ${ }^{4}$, Chris Lavy ${ }^{5}$, Kathryn H. Jacobsen ${ }^{6}$}

\author{
1. Department of Surgery, College of Medicine, University of Malawi, Blantyre, Malawi \\ 2. Beit CURE International Hospital, Blantyre, Malawi \\ 3. Leeds Institute of Rheumatic and Musculoskeletal Medicine, University of Leeds, Leeds, United Kingdom \\ 4. Centre for Global Surgery, McGill University Health Centre, Montreal, Quebec, Canada \\ 5. Nuffield Department of Orthopaedics, Rheumatology and Musculoskeletal Sciences; University of Oxford, Oxford, United Kindgom \\ 6. Department of Global and Community Health, George Mason University, Fairfax, Virginia, USA
}

Correspondence: Dr Wakisa Mulwafu (wmulwafu2@gmail.com)

\begin{abstract}
Injuries are a global public health concern because most are preventable yet they continue to be a major cause of death and disability, especially among children, adolescents, and young adults. This enormous loss of human potential has numerous negative social and economic consequences. Malawi has no formal system of prehospital trauma care, and there is limited access to hospital-based trauma care, orthopaedic surgery, and rehabilitation. While some hospitals and research teams have established local trauma registries and quantified the burden of injuries in parts of Malawi, there is no national injury surveillance database compiling the data needed in order to develop and implement evidence-based prevention initiatives and guidelines to improve the quality of clinical care. Studies in other low- and middle-income countries (LMICs) have demonstrated cost-effective methods for enhancing prehospital, in-hospital, and postdischarge care of trauma patients. We encourage health sectors leaders from across Malawi to take action to improve trauma care and reduce the burden from injury in this country.
\end{abstract}

\section{Introduction}

Injuries were responsible for approximately 4.7 million deaths worldwide in 2015, accounting for about $8.5 \%$ of all mortality. Injuries are also responsible for about 5.2\% of all years lived with disability. ${ }^{2}$ Injuries are a public health concern in part because they are a major cause of death and disability among children, adolescents, and young adults, and this enormous loss of human potential has numerous negative social and economic consequences. ${ }^{3}$ The Global Burden of Disease collaboration (via the GBD Results Tool, an online appendix to a series of papers published in 2016 in The Lancet by the Global Burden of Disease Collaboration that is available at http://ghdx.healthdata.org/gbd-resultstool) estimates that about $6.4 \%$ of all deaths in Malawi each year are due to injuries. The burden from injuries is especially high for young people, with injuries causing $14 \%$ of all deaths that occur among people who are aged 5 to 24 years.

There are numerous traumas that can cause physical damage: transport-related injuries, falls, drowning, burns, poisoning, industrial crush wounds and other types of exposure to mechanical forces, animal attacks, and other unintentional injuries as well as self-inflicted injuries, assaults and other forms of interpersonal violence, war and other armed conflicts, and other intentional injuries. In Malawi, the majority of injury deaths are due to unintentional injuries, and transport-related injuries account for nearly half of all unintentional injury deaths. ${ }^{1}$ Malawi has one of the highest rates of road traffic mortality per 100,000 residents of any country in the world. ${ }^{4}$ Overall, injuries are estimated to cause economic losses of up to $5 \%$ of GDP in low and middleincome countries, and road traffic deaths alone are estimated to cost up to $3 \%$ of global GDP. ${ }^{5}$ This means that mortality and disability resulting from traffic collisions and other types of injuries in Malawi may be playing a significant role in slowing down progress on socioeconomic indicators.

However, the general global pattern is that the allocation of resources to injury prevention and treatment remains well below the levels of support for infectious diseases and many other public health issues, with the resources available for injury interventions especially limited in low- and middleincome countries (LMICs). ${ }^{6,7}$ In addition, most LMICs do not have injury surveillance systems that compile injury data. Without a strong health information system, the true burden of injuries cannot be quantified and progress toward reducing the preventable burden of deaths and disability from injury cannot be monitored over time. Thus, the growing awareness that LMICs bear a heavy burden from injuries, most LMICs do not have the capacity needed to prevent trauma and to improve care of the injured persons from the time of the injury through the rehabilitation process.

This paper highlights the burden of trauma in LMICs such as Malawi and documents important and needed improvements in trauma care that will help in prevention of injuries and lead to improved care of injured persons. It also provides a roadmap for improving trauma care in Malawi.

\section{Injuries and trauma care in Malawi}

Malawi has a population of 17 million people, about $84 \%$ of whom live in rural areas. ${ }^{8}$ The country has one of the world's lowest income levels per person (in terms of gross national income per capita), at about US $\$ 250$ per person, and the majority of residents live below the international poverty line. ${ }^{8}$ The majority of health services are offered by Ministry of Health facilities, and most services at public hospitals and clinics are free for patients. However, the other direct and indirect costs of injury care-transportation, lost income, and other expenses-make injuries costly to individuals and families and, by extension, to the country as a whole.

Malawi has no formal system of prehospital trauma care. Prehospital trauma care on the scene of an accidentwhether that is roadside care after a traffic collision, initial atthe-worksite care for serious traumas sustained at industrial 
workplaces, or first aid provided at other places where people have sustained traumatic injuries prior to transporting the victims to a healthcare facility - is typically offered by first responders who have no training and therefore lack the knowledge and skills to appropriately provide first aid to moderately or severely wounded people. ${ }^{9}$ The lack of trained emergency medical technicians, ambulances, and other tools for providing skilled prehospital care means that some injured people who could have survived instead end up dying at the site where their injury occurred. Others end up with lengthy hospital stays and severe disabilities that could have been shorter and milder if they had received better first aid at the site of a trauma, such as having steps taken to support breathing, stop bleeding, and safely extricate people from damaged vehicles without causing greater physical damage.

Most Malawians also have limited access to hospital-based trauma care. While district hospitals can provide some emergency trauma care and surgeries, only central hospitals are equipped to provide advanced orthopaedic surgery. ${ }^{10}$ There are only a few central hospitals in Malawi, and they are located in urban areas. It may be impossible to transport an injured rural patient to a central hospital in time for surgical interventions to be save that individual's life. Furthermore, in-hospital care of injured persons is often sub-optimal at hospitals due to a lack of appropriate infrastructure, adequate numbers of trained personnel, and the necessary equipment and supplies to provide life-saving and disabilitypreventing treatment. ${ }^{11}$ These conditions are common across sub-Saharan Africa. ${ }^{12,13}$

In high-income countries, the establishment of inclusive trauma systems that provide a comprehensive spectrum of care to all injured patients within a well-defined geographic area has contributed to a reduction in injury-related mortality and disability. ${ }^{14}$ Comprehensive trauma systems ensure access to the entire patient pathway from point of injury and prehospital care through emergency department resuscitation and, if required, specialist emergency surgical treatments followed by rehabilitation that allows for reintegration into the community. ${ }^{15}$ Preventing injuries through cost-efficient interventions (such as enforcing speed limits for drivers, supervising children when they are playing near fires or bodies of water, and storing household chemicals and medications out of reach of young children) is a necessary complement to increasing access to quality post-trauma services. ${ }^{16} \mathrm{~A}$ full-care system that incorporates prevention strategies and clinical care would be incredibly valuable for reducing the burden of injuries in Malawi, if a funding mechanism was in place to support expanded public health care.

\section{Improved injury surveillance}

The World Health Organization considers robust health information systems to be a fundamental component of functioning health systems, as important for the delivery of quality health services as safe facilities and a well-trained workforce. ${ }^{17}$ Injuries are a common cause of hospital visits in Malawi, ${ }^{18,19}$ and they are also a common cause of preventable death. ${ }^{20}$ However, these observations are based on studies at a limited number of facilities in a limited number of locations. There is no national injury surveillance system, and as a result the estimates of the national burden from injuries - and the estimates of the burden from specific injury causes such as traffic collisions, falls, drowning, burns, poisoning, occupational hazards, animal attacks, selfharm, interpersonal violence, and others-are based on mathematical models and best guesses but the true burden of injuries in the country is not known.

The absence of a national injury surveillance system also means that priorities for injury prevention interventions are based on a limited foundation of evidence about the types and causes of injuries in Malawi. The Ministry of Health's efforts in curbing trauma in Malawi are outlined in the National Non-communicable Diseases Action Plan (2012-2016). One of the goals spelled out in the Plan is to reduce the incidence and impact of trauma and related disabilities in Malawi through effective policy action, targeted primary prevention interventions, effective emergency and rehabilitative services, strengthened research capacity, and effective advocacy. The formulation of effective policies and other types of health interventions is dependent on a solid body of evidence on which to make decisions. Improved data are also necessary for tracking progress toward achieving prioritized goals.

One components of a health information systems is a trauma registry, a hospital-based data collection system that provides information for evaluating the outcomes of trauma care. Trauma registries allow gaps in injury prevention and care to be identified. This is essential not only for assessing the quality of and improvement in care of trauma patients, but also for introducing policy and practice measures to address the identified gaps, such as education programs, improved infrastructure, and traffic laws that will protect residents from preventable harm. In many high-income countries, trauma registries have been recognized as one of the vital tools for providing evidence to support improvements in trauma care practices. ${ }^{21}$ Establishing a trauma registry where none has previously existed is a challenging task..$^{22}$ Nevertheless, it is a feasible project even in low-income countries, and countries with limited resources have been able to establish successful trauma registries that are guiding decision making about health spending priorities. ${ }^{23}$ Studies have shown that the routine data collected by district hospitals in Malawi has inadequate content and quality to inform prevention and improve trauma care. ${ }^{18,24}$ However, several institutions in Malawi have established pilot surveillance systems in their trauma wards. For example, Kamuzu Central Hospital $(\mathrm{KCH})$, a referral facility in the central region of the country, has established a database for all trauma patients seen at the hospital. ${ }^{19}$ The presence of these hospital-based systems does not negate the need for a national registry and incorporation of district hospitals in data collection and analysis. The lessons learned from these pilot projects will be valuable as surveillance systems are scaled up. Additional economic analyses of surveillance system data may allow for identification of the costs of trauma to the health system and the scaling up of cost-effective interventions that might lead to cost savings for the health system. Establishing and strengthening injury surveillance systems, regularly assessing trauma databases for completeness and accuracy, and making recommendations to improve their content will ensure that the data are representative, reliable, and useful for planning and implementation purposes.

Without reliable information, it is difficult to allocate resources which will achieve the greatest impact in injury prevention, treatment, and rehabilitation of injured persons. A national trauma registry will work best if it is implemented and supported by the Ministry of Health as part of their commitment to using data-driven and evidence-based approaches to promoting clinical guidelines, managing 
health resources, and overseeing health financing. ${ }^{25} \mathrm{~A}$ second source of valuable information about road traffic injuries, in particular, is the data collected by traffic police. One of the limitations of hospital-based trauma registries is that they do not include cases that do not present to a hospital, including fatalities. Collating traffic police and hospital data gives a better estimate of true burden of injuries than using each source in isolation. Injury data collected by the police have been found to be incomplete and unclean (such as including duplicate entries), but these problems can be resolved when police officers understand how the data will be used to improve safety and supervisors have a commitment to data quality. ${ }^{26}$ The Ministry of Health can work with the police to improve data sharing protocols.

\section{Prehospital care}

Malawi does not have a formal prehospital care system. Opportunities to address gaps in emergency care include providing first aid training for likely first responders, including community leaders and commercial drivers as well as police, fire fighters, and ambulance drivers; implementing an emergency communication system with a reliably functioning telephone number and a coordinated response among emergency service providers such as police, fire fighters, and hospitals; purchasing more ambulances to provide transportation to hospitals, and equipping those vehicles with critical supplies, including working radios and lifesaving devices such as defibrillators; and training paramedics to provide pre-hospital care. ${ }^{27,28}$ At present, none of these structures for prehospital care-first aid training, a national hotline for calling for help, ambulances, and paramedics-is available in Malawi. ${ }^{9}$ This lack of prehospital care is causing many unnecessary deaths each year. Deaths from preventable causes at any age are a tragedy, and there is an especially high societal cost from injuries because the majority of injury deaths occur among young people who would otherwise have expected to live for several more decades while contributing to economic productivity through work and as caregivers for young children and older adults. The need to improve prehospital care system in Malawi cannot be overemphasised when considering changes to the health system.

Although it would be ideal to have professional emergency medical personnel available to provide prehospital care at every trauma scene, budgetary realities make this a distant goal in low-income countries like Malawi. However, there is an urgent need to take steps to improve prehospital trauma care to reduce trauma-related morbidity and mortality. A graduated development and upscaling of the prehospital system can accompany scaling up of the rest of the trauma care pathway in Malawi (Figure 1). A first step would be the development of a formal network of community leaders, police, commercial drivers, and other lay volunteers who are trained in basic first aid and equipped to respond to emergency trauma at the location of an injury as well as while the patient is being transported to a hospital. First aid training courses in sub-Saharan African countries has increased access to prehospital care in those places, and those training courses could be adapted for use in Malawi and other countries. ${ }^{29,30}$ Ghana has deployed trained emergency management technicians across the country to improve the quality of prehospital emergency care. ${ }^{31}$ Nigeria has increased the number of ambulances available to transport trauma patients. ${ }^{32}$ The scaling up of first aid training in Malawi should be accompanied by improved communication between first responders and professionals and by better transportation options for injured people, which will need to be developed in a manner consistent with the local needs and capacities.

\section{In-hospital care}

Lack of appropriate infrastructure, trained personnel, and adequate equipment and supplies in most district and central hospitals has resulted in suboptimal care of injured cases. ${ }^{11,34}$ The greatest strides in improving injury survival and recovery rates will likely be achieved if each health facility treating trauma patients has a dedicated accident and emergency (A\&E) unit which is well equipped. This can be done in a phased approach starting with hospitals along M1 road that is the country's main highway and extends from the northern border of the country all the way to the southern border. The success of A\&E units is dependent on all staff working in A\&E units having received standardised emergency trauma management training as well as continuing education at frequent intervals. 35,36 This will ensure standard and effective treatment of all trauma patients presenting to hospitals with traumatic injuries. Most district and central hospitals have staffing and equipment shortages, and there is lack of trauma care training for clinical staff at central and district hospitals. ${ }^{11}$ However, most clinicians at all levels of care-physicians and surgeons, clinical officers, nurses, and others-are eager for opportunities to learn new skills that will let them better serve their patients. Opportunities for advanced training are likely to be welcomed and appreciated as well as effective at improving patient care. ${ }^{37-40}$

\section{Post-discharge care}

The current demand for physiotherapy and rehabilitation services in Malawi cannot be met by the current workforce. ${ }^{41}$ Patients with severe injuries often experience lengthy periods of inpatient hospitalisation with prolonged bed rest, especially when they must wait for surgery due to demand for theatre time, lack of skilled personnel, or lack of needed surgical instruments and implants. Longer periods of physical inactivity delays recovery and leads to less favourable outcomes. A significant proportion of trauma patients become permanently disabled, and this is associated with a reduced quality of life for the individual as well as adverse economic consequences for the entire family. ${ }^{42}$ Trauma registries that track long-term outcomes for injured individuals will help to quantify the unmet need for physiotherapy and rehabilitation as well as documenting the resources available for this level of care. The trauma care process cannot be considered complete until patients have received necessary rehabilitation care and regained the function necessary to return to their homes and to regular routines.

\section{Trauma research}

There is an urgent need for more significant investment in trauma research in Malawi all along the spectrum of trauma care from prevention through rehabilitation. This includes descriptive epidemiological research that aims to understand the burden of injuries and associated disability and mortality in Malawi as well as clinical and economic research to test the most effective strategies for reducing the burden from injuries and improving the clinical care and outcomes trauma patients. A national trauma research action plan and funding designated for this initiative will provide guidance and resource for research teams. 


\section{Concluding remarks}

Although the Ministry of Health has a key role to play in injury prevention and improved trauma care, there is need for the involvement of leaders from many sectors, including education, transport, non-governmental organisations, academia, and others. Collaboration among these stakeholders will ensure that plans to reduce the burden of injuries and improve trauma care in Malawi are translated into action. The establishment of a lead agency to oversee the development of an inclusive trauma system is important, but the success of such a program will require the support of clinicians and other leaders in the health sector. The plans needs to include all types of healthcare facilities and the full spectrum of care from the prehospital phase through hospitalisation and rehabilitation. The serious limitations in trauma care in Malawi have resulted in the loss of many lives and caused a lot of disability. This is not acceptable as Malawi develops. It is time for national action to reduce injuries. All members of the Medical Association of Malawi and others who work in the health sector are called upon to take part in making injury prevention and improved trauma care a reality.

\section{Competing interests}

All authors declare that they have no competing interests related to this work.

\section{References}

1. GBD 2015 Mortality and Causes of Death Collaborators. Global, regional, and national life expectancy, all-cause mortality, and causespecific mortality for 249 causes of death, 1980-2015: a systematic analysis for the Global Burden of Disease Study 2015. Lancet 2016; 388:1457-1544.

2. GBD 2015 Disease and Injury Incidence and Prevalence Collaborators. Global, regional, and national incidence, prevalence, and years lived with disability for 310 diseases and injuries, 1990-2015: a systematic analysis for the Global Burden of Disease Study 2015. Lancet 2016; 388:1545-1602.

3. Peden M, Surfield R, Sleet D, et al. World report on road traffic injury prevention. Geneva: World Health Organization; 2004.

4. Global status report on road safety 2015. Geneva: World Health Organization (WHO); 2015.

5. McMahon K, Dahdah S. The true cost of road crashes: valuing life and the cost of a serious injury. Hampshire, UK: International Road Assessment Programme (iRAP); 2008.

6. Hofman K, Primack A, Keusch G, Hrynkow S. Addressing the growing burden of trauma and injury in low- and middle-income countries. Am J Public Health 2005; 95:13-17.

7. Lagarde E. Road traffic injury is an escalating burden in Africa and deserves proportionate research efforts. PLoS Med 2007; 4:e170.

8. World development indicators 2016. Washington: World Bank; 2016

9. Chokotho L, Mulwafu W, Singini I, Njalale Y, MaliwichiSenganimalunje L, Jacobsen KH. First responders and pre-hospital care for road traffic accidents in Malawi. Prehospital Disaster Med 2017; 32:14-19.

10. Lavy C, Tindall A, Steinlechner C, Mkandawire N, Chimangeni S. Surgery in Malawi: a national survey of activity in rural and urban hospitals. Ann R Coll Surg Engl 2007; 89:722-724.

11. Chokotho L, Mulwafu W, Singini I, Njalale Y, Jacobsen KH. Improving hospital-based trauma care for road traffic injuries in Malawi. World J Emerg Med 2017; 8:85-90.
12. Chokotho L, Jacobsen KH, Burgess D, Labib M, Le G, Peter N, Lavy CBD, Pandit H. A review of existing trauma and musculoskeletal impairment (TMSI) care capacity in east, central, and southern Africa. Injury 2016; 47:1990-1995.

13. Chokotho L, Jacobsen KH, Burgess D, Labib M, Le G, Lavy CBD, Pandit H. Trauma and orthopaedic capacity of 267 hospitals in east, central, and southern Africa. Lancet 2015; 385(Suppl 2):S17.

14. Cameron P, Gabbe B, Cooper D, Walker T, Judson R, McNeil J. A statewide system of trauma care in Victoria: effect on patient survival. Med J Aust 2008; 189:546-550.

15. Lendrum RA, Lockey DJ. Trauma system development. Anaesthesia 2013; 61(Suppl 1):30-39.

16. Peden MM. World report on child injury prevention. World Health Organization; 2008.

17. World Health Organization. Everybody's business--strengthening health systems to improve health outcomes: WHO's framework for action.

18. Chokotho L, Mulwafu W, Jacobsen KH, Pandit H, Lavy C. The burden of trauma in four rural district hospitals in Malawi: a retrospective review of medical records. Injury 2014; 45:1065-1070.

19. Samuel JC, Akinkuotu A, Villaveces A, et al. Epidemiology of injuries at a tertiary care center in Malawi. World J Surg 2009; 33:18361841.

20. Chasimpha S, McLean E, Chihana M, et al. Patterns and risk factors for deaths from external causes in rural Malawi over 10 years: a prospective population-based study. BMC Public Health 2015; 15:1036.

21. O’Reilly GM, Gabbe B, Moore L, Cameron PA. Classifying, measuring and improving the quality of data in trauma registries: a review of the literature. Injury 2016; 47:559-567.

22. Mehmood A, Razzak JA, Kabir S, MacKenzie EJ, Hyder AA. Development and pilot implementation of a locally developed trauma registry: lessons learnt in a low-income country. BMC Emerg Med $2013 ; 13: 4$

23. O'Reilly GM, Joshipura M, Cameron PA, Gruen R. Trauma registries in developing countries: a review of the published experience. Injury 2013; 44:713-721.

24. Samuel JC, Akinkuotu A, Baloyi P, Villaveces A, Charles A, Lee CN, Miller W, Hoffman IF, Muyco AP. Hospital-based injury data in Malawi: strategies for data collection and feasibility of trauma scoring tools. Tropical doctor. 2010 Apr 1;40(2):98-9.

25. Shaban S, Eid HO, Barka E, Abu-Zidan FM. Towards a national trauma registry for the United Arab Emirates. BMC research notes. 2010 Jul 10;3(1):187.

26. Chokotho LC, Matzopoulos R, Myers JE. Assessing quality of existing data sources on road traffic injuries (RTIs) and their utility in informing injury prevention in the Western Cape Province, South Africa. Traffic Inj Prev 2013; 14:267-273.

27. Beuran M, Paun S, Gaspar B, et al. Prehospital trauma care: a clinical review. Chirurgia 2012; 107:564-570.

28. Sasser S, Varghese M, Kellerman A, Lormand JD. Prehospital trauma care systems. Geneva: World Health Organization; 2005.

29. Jayaraman S, Mabweijano JR, Lipnick MS, Caldwell N, Miyamoto J, Wangoda R, et al. First things first: effectiveness and scalability of a basic prehospital trauma care program for lay first-responders in Kampala, Uganda. PLoS One 2009;4:e6955. doi:10.1371/journal. pone. 0006955

30. Sangowawa AO, Owoaje ET. Building capacity of drivers in Nigeria to provide first aid for road crash victims. Inj Prev 2012;18:625. doi:10.1136/injuryprev-2011-040134 
31. Martel J, Oteng R, Mould-Millman Nk, Bell SA, Zakariah A, Oduro $\mathrm{G}$, et al. The development of sustainable emergency care in Ghana: physician, nursing and prehospital care training initiatives. J Emerg Med 2014;47:462-8. doi:10.1016/j.jemermed.2014.04.041

32. Adewole OA, Fadeyibi IO, Kayode MO, Giwa SO, Shoga MO, Adejumo AO, Ademiluyi SA. Ambulance services of Lagos state, Nigeria: a six-year (2001-2006) audit. West Afr J Med 2012;31:3-7.

33. Lavy C, Sauven K, Mkandawire N, et al. State of surgery in tropical Africa: a review. World J Surg 2011; 35:262-271.

34. Moroz PJ, Spiegel DA. The World Health Organization's action plan on the road traffic injury pandemic: Is there any action for orthopaedic trauma surgeons? J Orthop Trauma 2014; 28(Suppl 1):S11-14.

35. Quansah R, Abantanga F, Donkor P. Trauma training for nonorthopaedic doctors in low- and middle-income countries. Clin Orthop Relat Res 2008; 466:2403-2412.

36. Grimes CE, Mkandawire NC, Billingsley ML, Ngulube C, Cobey JC. The cost-effectiveness of orthopaedic clinical officers in Malawi. Trop Doct 2014; 44:128-134.
37. Nogaro MC, Pandit H, Peter N, et al. How useful are primary trauma care courses in sub-Saharan Africa? Injury 2015; 46:1293-1298.

38. Peter NA, Pandit H, Le G, Muguti G, Lavy C. Delivering trauma training to multiple health-worker cadres in nine sub-Saharan African countries: lessons learnt from the COOL programme. Lancet 2015; 385(Suppl 2):S45.

39. Qureshi JS, Young S, Muyco AP, et al. Addressing Malawi's surgical workforce crisis: a sustainable paradigm for training and collaboration in Africa. Surgery 2013; 153:272-281.

40. Fielder S, Mpezeni S, Benjamin L, Cary I. Point of view: physiotherapy in Malawi: a step in the right direction. Malawi Med J 2013; 25:83-85.

41. Kohler RE, Tomlinson J, Chilunjika TE, Young S, Hosseinipour M, Lee CN. "Life is at a standstill": quality of life after lower extremity trauma in Malawi. Qual Life Res 2017; 26:1027-1035. 